\title{
ESTRATÉGIAS TECNOLÓGICAS EM CADEIAS DE SUPRIMENTOS DO SETOR DE LINHA BRANCA
}

\section{TECHNOLOGICAL STRATEGIES IN SUPPLY CHAINS FROM THE DOMESTIC APPLIANCE INDUSTRY}

\author{
Aline Lamon Cerra ${ }^{1}$; Jonas Lucio Maia ${ }^{2}$; Alceu Gomes Alves Filho ${ }^{3}$ \\ ${ }^{1}$ Universidade Federal de São Carlos - UFSCar - São Carlos/SP - Brasil \\ alinelc@terra.com.br \\ ${ }^{2}$ Universidade Federal de São Carlos - UFSCar - São Carlos/SP - Brasil \\ jonasmaia@dep.ufscar.br \\ ${ }^{3}$ Universidade Federal de São Carlos - UFSCar - São Carlos/SP - Brasil \\ alceu@power.ufscar.br
}

\begin{abstract}
Resumo
A literatura que trata da Estratégia Tecnológica (ET), embora tenha evoluido, ainda pode ser considerada incipiente. As lacunas são ainda maiores quando se consideram as relações entre ETs de diferentes empresas, como é o caso de montadoras e de fornecedores em cadeias de suprimentos. Neste contexto, o objetivo deste artigo é identificar e analisar a ET de uma montadora do setor de linha branca no contexto de sua cadeia de suprimentos. Para isso, também são estudados três de seus fornecedores diretos (de primeiro nível). Os principais resultados deste estudo mostram que a montadora tende a contribuir para o desenvolvimento tecnológico brasileiro, na medida em que realiza atividades locais de $P \& D$, e ainda, o faz em conjunto com fornecedores. Dentre esses fornecedores, têm-se empresas que dominam o conteúdo tecnológico de componentes importantes para produtos de linha branca e, também, um conjunto de empresas nacionais de pequeno porte, as chamadas empresas familiares. A montadora deve despender esforços para desenvolver os fornecedores menos capacitados (passando-lhes conhecimentos) e garantir um desempenho adequado dos mesmos. Assim, pode-se dizer que a cadeia de suprimentos (composta por um conjunto heterogêneo de empresas) influencia sua ET.
\end{abstract}

Palavras-chave: Estratégia Tecnológica, Desenvolvimento de Produtos, Estratégia, Linha Branca.

\section{Introdução}

Os assuntos associados à tecnologia e inovação tecnológica fazem parte das tarefas gerenciais de todas as firmas e não apenas das de alta tecnologia (FORD, 1989), embora estas últimas possam ser definidas como aquelas que realizam esforços tecnológicos significativos e concentram suas operações na fabricação de novos produtos (FERNANDES et al, 2000).

A variedade de conceitos sobre tecnologia encontrada na literatura é, de acordo com Alves Filho (1991), conseqüência de diferentes visões e objetivos dos pesquisadores. Iglecias (2001) 
aponta algumas características comuns à maioria das definições apresentadas: a tecnologia é oriunda das ciências; deve ser orientada para um fim prático; deve ser reproduzida em escala industrial; e pode ser aplicada não apenas a bens e serviços, mas também ao processo produtivo e à sua gestão.

Segundo Boehe (2007), em pesquisa realizada junto a diversos setores industriais, o Brasil ainda pode ser considerado um país receptor de tecnologia, dado o menor número de unidades voltadas às atividades inovadoras e devido ao fato dos projetos aqui realizados serem voltados ao mercado interno e de países emergentes.

Apesar disso, os temas relacionados à tecnologia e à gestão de tecnologia vêm cada vez mais ganhando relevância (no Brasil e no mundo), pois tecnologia é entendida como fator crucial de competitividade em diversos setores econômicos.

Para a sobrevivência de firmas em mercados competitivos, Zahra e Nielsen (2002) propõem a integração de fontes internas e externas de tecnologia. Neste sentido, como fontes internas, podese mencionar a realização de pesquisa básica e aplicada (WILBON, 1999 apud RIEG, 2004). No que diz respeito às fontes externas de tecnologias, tem-se, dentre outras: i) compra no mercado, contratação de outras empresas, universidades e centros de pesquisa (HIPPEL, 1998 apud RIEG, 2004); ii) licenciamentos (HIPPEL, 1998 apud RIEG, 2004); e iii) alianças tecnológicas (HAGERDOOM; NARULA, 1996).

Cabe ainda citar o conceito de capacidade de absorção (absorptive capability), que se baseia na premissa de que organizações necessitam de conhecimentos adquiridos anteriormente para assimilarem e explorarem um novo conhecimento (COHEN; LEVINTHAL, 1990). Segundo HaroDomíngues et al (2007), a falta de capacidade de absorção, por outro lado, representaria um obstáculo para a construção de competências, dificultando o comportamento proativo da firma.

Neste contexto, pode-se constatar que a literatura sobre tais temas (tecnologia e inovação tecnológica) vem tornando-se mais rica e densa. Entretanto, no que se refere especificamente à Estratégia Tecnológica (ET), a literatura, embora tenha evoluído, ainda pode ser considerada incipiente. Não há ainda um conceito consagrado de Estratégia Tecnológica, embora algumas proposições tenham sido feitas.

Além de não existir ainda na literatura um consenso sobre o conceito de Estratégia Tecnológica, segundo Alves Filho (1991) há uma supervalorização de questões concernentes a Pesquisa \& Desenvolvimento (relacionada à Capacidade de Inovação) em detrimento das demais capacidades tecnológicas (Produção e Adaptação, Investimento (Aquisição), e Exploração e Proteção), apresentadas na seção a seguir. 
As lacunas são ainda maiores quando se consideram as relações entre Estratégias Tecnológicas de diferentes empresas, como é o caso de montadoras e de fornecedores em cadeias de suprimentos.

O setor industrial abordado neste trabalho é o de linha branca. Cabe mencionar que os produtos denominados linha branca são: refrigeradores, lavadoras automáticas, freezers verticais e horizontais, lava-louças, secadoras de roupas automáticas, fogões, condicionadores de ar e fornos microondas (ROTTA, 2004).

O objetivo deste artigo é identificar e analisar a Estratégia Tecnológica (ET) de uma montadora da linha branca no contexto de sua cadeia de suprimentos. Para isso, também são estudados e comparados três de seus fornecedores diretos (de primeiro níveis). Para atingir esse objetivo, foram realizados estudos de caso nas quatro empresas durante o ano de 2007, fundamentados em entrevistas semi-estruturadas. Nas empresas, as pessoas entrevistadas são aquelas ligadas à tecnologia de produtos, processos e gestão, ou seja, diretores ligados à área tecnológica, diretores industriais, além de gerentes de compras/suprimentos.

Assim, as questões centrais desta pesquisa são: A cadeia de suprimentos influencia a Estratégia Tecnológica da montadora? Quais seriam os principais aspectos da cadeia que influenciariam e diferenciariam a ET da montadora? Quanto aos fornecedores, quais as principais características que diferenciariam suas ETs?

Este trabalho encontra-se estruturado da seguinte forma: inicialmente apresenta-se a revisão da literatura sobre Estratégia Tecnológica e Gestão da Cadeia de Suprimentos. Em seguida, discorre-se sobre a apresentação e análise dos estudos de caso. Concluindo, têm-se as considerações finais e os possíveis desdobramentos do trabalho.

\section{Estratégia Tecnológica}

Em linhas gerais, a literatura sugere a necessidade das empresas empregarem tecnologia estrategicamente, ligando-a a estratégia competitiva da empresa, garantindo assim que tecnologia e estratégia dêem suporte uma à outra, habilitando a empresa para alcançar os melhores resultados em suas metas. A natureza desta ligação é usualmente articulada na ET da firma. Sobre o conceito de ET, algumas proposições têm sido feitas:

A Estratégia Tecnológica é o enfoque que a empresa adota para o desenvolvimento e uso da tecnologia, constituindo elemento essencial de sua estratégia competitiva (PORTER, 1985).

Ford (1989) afirma que a ET consiste em políticas, planos e processos para a aquisição e para o gerenciamento de conhecimentos e habilidades da empresa, e na exploração destes para o lucro.

Estratégia Tecnológica se refere ao conjunto de escolhas que a firma faz sobre o estado e 
qualidade do know-how incorporado a projeto, desenvolvimento e produção de seus produtos e/ou serviços (GIBBON; O’CONNER, 2003).

Estratégia Tecnológica abrange a aquisição, gestão e exploração de conhecimentos e recursos tecnológicos da organização para alcançar suas metas de negócios (SOLOMON, 2001 apud DAVENPORT et al, 2003).

Neste trabalho, entendemos a Estratégia Tecnológica como o conjunto de esforços que a empresa despende para aumentar suas capacidades tecnológicas e implementar mudanças, seja nos sistemas produtivos, seja em produtos, processos e em sua gestão:

\footnotetext{
A Estratégia Tecnológica diz respeito a um conjunto de esforços e ações da empresa no sentido de ampliar sua capacidade tecnológica, tanto no âmbito das atividades de P\&D como nas demais áreas da empresa, para a implementação da mudança técnica. Engloba esta última a criação de novas técnicas e mudanças não necessariamente novas, seja do ponto de vista da empresa, seja em relação às fronteiras tecnológicas internacionais (ALVES FILHO, 1991, p.27).
}

Desse modo, faz-se necessário abordarmos as capacidades tecnológicas e a mudança técnica: Bell e Pavitt (1993) definem capacidade tecnológica como os recursos necessários para gerar e administrar mudanças técnicas, incluindo habilidades, conhecimentos e experiências e estruturas e links institucionais. A mudança técnica, segundo estes mesmos autores, consiste na introdução de tecnologias em novos produtos ou processos através de investimentos, ou ainda, adaptação incremental e melhoria da capacidade de produção existente.

Dahlman et al (1987); Westphal et al (1985), sugerem três tipos de capacidades abarcadas pela ET:

- Capacidade de Inovação: para criar novas tecnologias, desenvolver novos produtos ou serviços. Trata-se da capacidade para introduzir mudanças técnicas (radicais ou incrementais).

- Capacidade de Investimento (Aquisição): para adquirir tecnologia, para substituir, expandir e implantar instalações, adaptadas às condições de investimento;

- Capacidade de Produção e Adaptação: para operar as instalações produtivas, tendo em vista a obtenção de eficiência produtiva; abrange, além da produção, as possíveis adaptações da tecnologia.

- Capacidade de Exploração e Proteção de Tecnologias (sendo esta quarta capacidade sugerida por Ford, 1989): para vender ou prestar serviços no mercado a partir de tecnologias dominadas (ou comercializar as próprias tecnologias desenvolvidas) e também para implementar medidas que impeçam que conhecimentos adquiridos sejam copiados por concorrentes. 
As fronteiras entre esses quatro tipos de capacidade tecnológica não são claras, mas é certo que investimentos e esforços específicos são requeridos para cada tipo de capacidade (WESTPHAL et al, 1985 apud ALVES FILHO, 1991).

Estas capacidades não estão isoladas e há relações e sinergias entre elas. Desse modo, os elementos de uma ET analisados na prática das empresas estudadas são: as Capacidades Tecnológicas e as Mudanças Técnicas em produtos e processos. Cabe mencionar que as mudanças técnicas na área de gestão não são abordadas neste trabalho empírico.

As principais informações relacionadas às Capacidades Tecnológicas levantadas nas empresas apresentam-se Quadro a seguir:

Quadro 1. Indicadores para a avaliação das Capacidades Tecnológicas.

\begin{tabular}{|c|c|}
\hline $\begin{array}{l}\text { Capacidade de } \\
\text { Inovação }\end{array}$ & $\begin{array}{l}\text { A existência de P\&D estruturado ou não empresa; a autonomia tecnológica da subsidiária em } \\
\text { relação à matriz estrangeira; o número de engenheiros/cientistas que trabalham em DP; o } \\
\text { lançamento de novos produtos, os projetos recentes e a introdução de mudanças significativas } \\
\text { em processos de produção; e o envolvimento dos fornecedores nas atividades de DP local. }\end{array}$ \\
\hline $\begin{array}{l}\text { Capacidade de } \\
\text { Investimento/ } \\
\text { Aquisição }\end{array}$ & $\begin{array}{l}\text { Os projetos de aquisição de nova tecnologia para a empresa; a relação com centros de } \\
\text { pesquisa e universidades para o desenvolvimento de projetos e/ou aquisição de tecnologia; e } \\
\text { a participação em redes de cooperação para desenvolvimento de novas tecnologias. }\end{array}$ \\
\hline $\begin{array}{l}\text { Capacidade de } \\
\text { Produção e } \\
\text { Adaptação } \\
\end{array}$ & $\begin{array}{l}\text { As mudanças incrementais (e as fontes dessas mudanças) em produtos e processos de } \\
\text { produção; e a estrutura organizacional que viabiliza os contatos entre a Engenharia e a } \\
\text { fábrica. }\end{array}$ \\
\hline $\begin{array}{l}\text { Capacidade de } \\
\text { Exploração e } \\
\text { de Proteção }\end{array}$ & $\begin{array}{l}\text { A existência de projetos nas empresas de exploração comercial de tecnologias dominadas (se } \\
\text { a empresa compra ou licencia tecnologias de produto e processo desenvolvidas por outras } \\
\text { empresas para incorporar em seus próprios produtos e processos e se explora (vende) } \\
\text { tecnologias por ela desenvolvidas). } \\
\text { As medidas implementadas para que o conhecimento adquirido não seja passado para a } \\
\text { concorrência. }\end{array}$ \\
\hline
\end{tabular}

Fonte: Cerra (2008).

A análise das ETs das empresas, no âmbito das cadeias de suprimentos, parte da análise individual das Capacidades Tecnológicas de cada empresa. As Capacidades Tecnológicas e as Mudanças Técnicas da montadora são então identificadas. Do mesmo modo, são feitas as análises das ETs das empresas fornecedoras.

\section{A Gestão da Cadeia de Suprimentos (Supply Chain Management)}

Uma cadeia de suprimentos, segundo Chopra e Meindl (2003), engloba todos os estágios (clientes, varejistas, distribuidores, fabricantes e fornecedores) envolvidos, direta ou indiretamente, no atendimento de um pedido ao cliente.

O objetivo principal da Gestão da Cadeia de Suprimentos (GCS) é tornar os processos de negócios mais eficientes e eficazes, reduzindo custos, níveis de estoque, melhorando a qualidade e criando vantagem competitiva e valor para a cadeia de suprimentos (ALVES FILHO et al, 2001). 
Alves Filho et al (2004) consideram a GCS como um corpo de conhecimentos ainda em construção. Os autores indicam que a literatura que trata do tema, tanto a de cunho mais prescritivo como a de cunho empírico, assume um conjunto de pressupostos que em muitos casos são enunciados como princípios norteadores de práticas de gestão mais eficazes, e como se o conjunto de tais pressupostos pudesse ser adotado e ser o mais eficaz e eficiente em quaisquer circunstâncias.

Com base no trabalho de Alves Filho et al (2004), os principais pressupostos da GCS, que se interrelacionam, são:

- A competição no mercado ocorre no nível das cadeias e não apenas no nível das empresas (CHRISTOPHER, 1992). Isto significa que a empresa não pode ser competitiva de forma isolada.

- O alinhamento das estratégias das empresas com a da cadeia de suprimentos é fundamental à melhoria de desempenho na relação entre fornecedores e clientes (HANDFIELD; NICHOLS (1999) apud ASSUMPÇÃO (2003)). Segundo os autores, esse alinhamento proporciona habilidades para melhoria de desempenho da empresa desde que haja clareza na visão de seu papel na cadeia de suprimentos e realização conjunta de atividades de aprendizado e inovação.

- O número de fornecedores tende a diminuir (TAN, 2002) e eles passam a ser hierarquizados de acordo com o nível que ocupam na cadeia (MIRANDA, 2002). Pires (2004) também indica a tendência de uma reestruturação e consolidação da base de fornecedores e clientes, cujo objetivo é, segundo o autor, definir um conjunto de empresas com os quais se deseja construir parcerias.

- Deve haver a coordenação da cadeia. Para alcançá-la, todos os estágios devem realizar ações que, em conjunto, aumentem os lucros da cadeia de suprimentos. Isto requer que cada estágio leve em consideração o impacto que suas ações exercem sobre outros estágios (CHOPRA; MEINDL, 2003).

- Deve haver um fluxo bidirecional de produtos (materiais e serviços) e informações entre todas as empresas pertencentes a cadeia de suprimentos (LAMBERT et al, 1996).

- As empresas se voltam à estratégia de outsourcing, a expressão em inglês para o termo terceirização (GIOSA, 1993 apud TRATT et al, 2006).

- Faz-se necessário uma verdadeira cooperação entre as firmas envolvidas no fornecimento do produto final (LAMMING, 1993), e, assim, as empresas passam a investir em parcerias. Parcerias são motivadas, segundo (Kogut, 1988; Hagedoorn, 1993; Eisenhardt e Schoonhoven, 1996 apud Lorenzoni e Lipparini, 1999), dentre outras coisas, pela necessidade de, partilhar riscos relacionados a investimentos em P\&D, comprimir o tempo de desenvolvimento de novos produtos, buscar novas oportunidades 
tecnológicas, obter eficácia na produção e ganhar acesso a novos mercados e habilidades.

- As empresas devem buscar fornecedores que sejam capazes de aceitar o desenvolvimento de um relacionamento de longo prazo com base na confiança mutua (CHRISTOPHER,1992).

- As empresas devem investir no desenvolvimento de fornecedores, que, segundo Handfield et al (2000), abrange qualquer atividade que um comprador empreende para melhorar as capacidades de desempenho de um fornecedor para satisfazer as suas necessidades de compras em curto prazo ou longo prazo. Com freqüência, são feitas avaliações formais dos fornecedores e muitas empresas têm estabelecido programas de treinamentos para seus fornecedores para auxiliá-los a alcançar metas de desempenho superiores.

- Outra prática que tem se expandido no contexto da GCS é o envolvimento conjunto das empresas em P\&D (ELLRAM, 1991 apud MIRANDA, 2002) e o envolvimento de fornecedores no processo de desenvolvimento e fabricação de novos produtos (TAN, 2002). O chamado "Early Supplier Involvement (ESI)", ou seja, o envolvimento de fornecedores desde as fases iniciais do projeto do produto, permite que o fornecedor traga a sua competência e know-how a serviço de um produto desenvolvido mais rapidamente, a custo menor e com mais qualidade (SANTOS; FORCELLINI, 2005).

A discussão de Alves Filho et al (2004), tomada como base nesta seção, sugere que as abordagens de GCS devem incluir uma etapa inicial de "verificação dos pressupostos", ou de identificação da configuração da cadeia de suprimentos, pois, por meio desta, poderiam ser desvendados os tipos de contextos em que as relações entre as empresas e a GCS poderiam se desenvolver.

\section{Estudos de Caso}

\subsection{O setor de linha branca}

A indústria de linha branca chegou ao Brasil no final dos anos 40, na fase inicial da política de substituição de importações. O setor ficou caracterizado por um número reduzido de grandes empresas familiares de capital nacional e dois grandes grupos transnacionais, que dominavam, direta ou indiretamente, as demais companhias, formando um oligopólio (MARTINEZ, 2004).

O crescimento da demanda por estes produtos nos países desenvolvidos e o aumento de sua difusão ocorreu na década de 70. No entanto, verificou-se na década seguinte um processo de 
desaceleração da demanda nesses países, chegando a um período de estagnação nos anos 90 . Segundo Rotta (2004), nos Estados Unidos e Europa presenciava-se a saturação dos mercados.

Com isso, os grandes grupos internacionais procuraram novos mercados, voltando-se aos mercados emergentes como a América Latina, o Leste Europeu e o Sudeste Asiático. As empresas brasileiras foram gradualmente sendo incorporadas por poucos e grandes grupos estrangeiros, ganhando acesso a inovações e iniciando um processo de rearranjo patrimonial que acompanhava a tendência mundial (GITAHY; CUNHA, 1998 apud MARTINEZ, 2004). Uma das principais conseqüências foi a desnacionalização do capital produtivo que, até então, tinha forte participação de empresas familiares nacionais.

Mais especificamente, foi a partir da metade da década de noventa que intensificou-se o processo de reestruturação produtiva e organizacional nas indústrias nacionais, que diferenciaram e sofisticaram os produtos, ampliaram a capacidade produtiva, modernizando ou abrindo novas plantas (ROTTA, 2004).

Os investimentos externos possibilitaram a difusão de tecnologias no Brasil permitindo a paridade de desempenho internacional tanto em processos, quanto no lançamento de novos produtos. Este último foi um grande avanço para o mercado brasileiro, que ofertava produtos obsoletos frente aos mercados de suas matrizes.

No que diz respeito a cadeia de suprimentos, também foco desta pesquisa, tem-se que o volume de recursos dos materiais adquiridos dos fornecedores representam grande importância no custo de fabricação do produto. Neste setor, os fornecedores de primeiro nível seriam as empresas que fornecem componentes usinados e os fornecedores de segundo nível seriam os distribuidores de aço (MARTINS, 1999).

\subsection{Apresentação e descrição das empresas}

De Modo a não identificar as empresas, a montadora será aqui denominada "Montadora A", e os fornecedores numerados de 1 a 3 :

\subsection{Montadora A}

Em 1925 o primeiro refrigerador foi lançado pela empresa no mundo. No ano seguinte, foi inaugurada a primeira unidade no Brasil, com vendas diretas no estado de São Paulo-SP.

Atualmente existem cinco unidades fabris localizadas no Brasil. Cada uma delas é voltada à diferentes unidades de negócios do grupo, mas há grandes interações entre elas.

Desde a implantação da primeira unidade até os dias de hoje a empresa vem crescendo e se modernizando. Adquiriu controle acionário de outros grupos e, com isso, incorporou diversas marcas, diversificou os produtos e se consolidou no mercado da América Latina. Em paralelo a tais 
mudanças, foi se certificando em normas de qualidade, recebendo prêmios em função de suas políticas eficazes de proteção ao meio ambiente, etc.

Vale ressaltar que atividades tais como Desenvolvimento de Produtos (DP) e Compras, relevantes para este estudo, não estão centralizadas na unidade aqui estudada. Desse modo, na Montadora A, os assuntos relativos a DP e Compras são tratados por funcionários que interagem com as pessoas da planta onde os mencionados setores se situam.

$\mathrm{Na}$ unidade estudada existem quatro linhas de montagem principais: uma voltada à produção de fogões, uma para freezers e duas para lavadoras. Cada um desses produtos apresenta uma série de modelos, com variações dentro de cada modelo. Além dessas, existem "linhas de apoio" (denominação dada por um dos entrevistados), tais como: estamparia, injeção de plásticos, linhas de montagem de transmissões e gabinetes de lavadoras, dentre outras.

Neste contexto, peças de maior porte são fabricadas internamente, assim como alguns componentes poliméricos (50\% do volume utilizado) e peças metálicas.

De acordo com o Supervisor de Engenharia Industrial da Montadora A, o volume produzido de fogões corresponde a aproximadamente $30 \%$ do total fabricado na planta, o de lavadoras 30\% e o restante, $40 \%$, diz respeito à parcela da produção que é voltada aos freezers.

As prioridades competitivas da montadora são Flexibilidade (de volume e de produtos) e redução de custos, sendo que Qualidade e o cumprimento de prazos de entrega seriam fatores qualificadores, e não ganhadores de pedidos.

A empresa vem implementando seu próprio sistema de manufatura, baseado nos aspectos da Produção Enxuta e pasou por uma fase de terceirização de componentes.

A unidade apresenta capacidade instalada de produção para aproximadamente 130.000 unidades/mês e atualmente a produção real é de cerca de 110.000 unidades/mês. A montadora A conta com aproximadamente 1300 funcionários e é a proprietária dos equipamentos utilizados por alguns fornecedores em suas respectivas plantas, o que, segundo o entrevistado, representa um grande patrimônio da empresa.

A partir de 2007 a unidade aumentou a diversidade de produtos e a capacidade produtiva, por meio da aquisição de novos equipamentos. Além disso, houve a modificação e introdução de novas matérias-primas, que gerou reduções de custos.

Para o mercado de reposição a empresa destina um volume muito pequeno da produção, e cerca de 5\% é exportada. Seus clientes são Casas Bahia, Carrefour, Ponto Frio, etc.

\subsubsection{Estratégia Tecnológica da Montadora A}


A planta estudada neste trabalho foi adquirida pelo grupo multinacional ao qual pertence na década de 90. Um dos aspectos por ela mais valorizados é flexibilidade, tanto a de volume de produção como também a de mix de produtos.

No que diz respeito à flexibilidade de volume, deve-se considerar que a demanda do setor passa por sazonalidades e, além disso, os pedidos dos clientes podem ser alterados durante todo o ano. Neste contexto, a empresa vem operando com capacidade ociosa.

Segundo o entrevistado, dentre as plantas do grupo instaladas no Brasil, a Montadora A é a que apresenta mais condições de expansão de atividades, com destaque para a produtiva.

A diversidade de modelos de produtos, desse modo, tem sido crescente. Entraram novos concorrentes no mercado e assim a flexibilidade de produtos tornou-se ainda mais importante para a empresa, que tem buscado atingir as diversas camadas da população.

Outra prioridade competitiva da empresa enfatizada no decorrer das entrevistas foi custos. Com o objetivo de reduzir custos, a montadora vem implementando técnicas e normas de qualidade, princípios do sistema de produção enxuta e ferramentas como por exemplo o Seis Sigma. A intenção é repassar aos fornecedores Tai aplicações, a fim de que estes reduzam os preços dos componentes à ela entregues.

Neste contexto, a empresa vem demonstrando esforços no sentido de ampliar as Capacidades de Inovação, Investimento e de Produção e Adaptação.

Apesar do fato do setor voltado às atividades de DP estar situado em outra planta do grupo, existe na Montadora A uma estrutura (composta por 10 engenheiros) voltada às atividades tecnológicas que vem crescendo e ganhando autonomia. Assim, a Engenharia da Montadora A acompanha os desenvolvimentos tecnológicos brasileiros, apoia tais atividades e se encarrega das mudanças ou inovações necessárias nos processos de produção (Capacidade de Inovação).

Cabe mencionar que a matriz estrangeira apresenta como estratégia a descentralização de atividades de DP, sendo que os produtos destinados ao mercado brasileiro são desenvolvidos localmente, com pouca (e decrescente) dependência da matriz. Neste contexto, apenas 5\% da produção nacional é exportada (principalmente à Argentina e outros países da América Latina).

Com a entrada dos novos concorrentes no mercado, muitos fornecedores surgiram e se especializaram na fabricação de componentes importantes, de modo que as montadoras do setor passaram a terceirizar boa parte deles. "Já não compensava mais investir recursos na produção de certos componentes", disse um dos entrevistados. Além disso, novos produtos demandaram novos componentes e, principamente no segmento de eletrônicos, as montadoras começaram a ficar mais dependentes em termos de conhecimentos.

Neste contexto, a empresa busca por conhecimentos junto à matriz estrangeira (apesar da autonomia tecnológica local ser crescente) e junto a fornecedores (ex.: compressores 
(refrigeradores), fornos (fogões) e painéis eletrônicos (lavadoras de roupas). Assim, a empresa prioriza também a Capacidade de Investimento (Aquisição). Vale lembrar que a empresa, com esta finalidade, não recorre à universidades e centros de pesquisa, onde apenas realiza testes específicos.

A Capacidade de Produção e Adaptação é outra que se destaca dentre as prioritárias para a empresa. Nesse sentido, existe um programa (corporativo) denominado IPDP - em português, "Desenvolvimento Integrado de Produto e Processo".

Este programa tem como objetivo fortalecer as relações entre as pessoas que desenvolvem os produtos e processos, e aquelas que os implementam nas fábricas.

$\mathrm{Na}$ Montadora A especificamente, a autonomia para desenvolver e gerar melhorias em processos de produção é crescente e os engenheiros responsáveis constituem o elo entre a fábrica e o setor que desenvolve os produtos da outra planta.

Quanto às demais capacidades (Capacidade de Exploração e Proteção), a montadora não tem demonstrado esforços no sentido de ampliá-las.

As mudanças técnicas realizadas nos produtos não são realizadas pelos engenheiros da Montadora $\mathrm{A}$, diferentemente do que acontece em relação às mudanças em processos.

As mudanças técnicas realizadas nos processos de produção são, em sua maioria, melhorias incrementais que podem (ou não) estar relacionadas à introdução de um novo modelo de produto (desenvolvido na outra planta do grupo).

\subsubsection{Cadeia de Suprimentos da Montadora A}

Inicialmente abordaremos as características da estrutura da cadeia de suprimentos da Montadora A.

O setor de Compras, assim como o de Desenvolvimento de Produtos, concentra-se em outra unidade do grupo, em Curitiba. Neste contexto, a maior parte dos fornecedores (70 a 80\%) abastece ambas as plantas.

Com a presença de alguns fornecedores exclusivos e com a necessidade de resoluções rápidas de problemas de fornecimento da Montadora A, nesta, criou-se em janeiro de 2007 um cargo na área de Compras.

Este cargo, ocupado por um engenheiro que trabalhava no setor da Qualidade, possui autonomia para negociar diversos assuntos relacionados às transações com fornecedores, com exceção de preços de componentes. Desse modo, seleciona, desenvolve e avalia fornecedores, resolve problemas de qualidade, negocia prazos e lotes entregues, etc.

Além disso, pode comprar itens indiretos e, neste caso, necessita de aval do Setor de Compras da outra unidade quando o valor negociado ultrapassa 80.000 reais. 
A Montadora A conta com 346 fornecedores ativos, número que aumentou com o crescimento do volume de produção. Como a estimativa é a de que em 2008 o volume de produção cresça significativamente, novos fornecedores estão sendo selecionados e, em alguns casos, desenvolvidos.

O porte dos fornecedores é bastante variado, mas predominam-se as empresas de médio porte. No caso das grandes empresas metalúrgicas, segundo os entrevistados, as negociações "são mais complicadas".

Algumas pequenas empresas fornecem exclusivamente para a Montadora A e alguns itens são importados, como por exemplo, as placas eletrônicas.

Existem vários fornecedores de módulos e a tendência é a de que que empresa adquira cada vez mais produtos de maior valor agregado. Exemplos: a cavidade do fogão já chega à montadora montada e com isolante térmico, painel do freezer, montagens simples, etc.

A seguir trataremos das relações entre empresas dentro da cadeia de suprimentos desta montadora.

Com a criação do cargo de Compras na Montadora A foi possível, segundo o entrevistado, “... exigir mais dos fornecedores”. Faz-se, nesta unidade, seleção, desenvolvimento e avaliação de fornecedores.

Em geral, as relações com fornecedores são de longo prazo e a política de suprimentos predominante é a de manter um fornecedor por item terceirizado, pois nestes a montadora investe em equipamentos e não compensaria duplicá-los. Desse modo, a empresa se protege de tornar-se dependente de alguns fornecedores.

No caso de alguns componentes, como por exemplo o compressor, a Montadora os adquire de dois fornecedores, $50 \%$ de cada um deles.

O processo de seleção de fornecedores, que acontece com a participação do pessoal da unidade de Curitiba, envolve uma equipe multidisciplinar (Qualidade, Logística, Produção, etc), da qual alguns representantes visitam a planta dos fornecedores para avaliá-los. Sendo aprovado para o fornecimento, inicia-se o seu desenvolvimento.

No desenvolvimento de fornecedores a Montadora A primeiramente passa as especificações de como os componentes devem ser fabricados e entregues. Nos casos em que os fornecedores apresentam dificuldades para atingir as exigências, a montadora indica um funcionário para que ele permaneça na planta do fornecedor para treiná-lo durante o tempo necessário, que geralmente é de 1 a 2 semanas.

Os fornecedores ativos são avaliados mensalmente de acordo com índices de peças defeituosas, não considerando o cumprimento de prazos de entregas. Desse modo, a empresa estabelece um Índice de Qualidade de Fornecimento para cada um deles. 
Os fornecedores que apresentam mais problemas têm, novamente, funcionários da montadora em suas plantas para auxiliá-los. Porém, em alguns casos ele pode ser substituído.

Segundo o entrevistado, a medida que efetivamente fez com que os fornecedores reduzissem os problemas de qualidade foi o estabelecimento, nos contratos, de pagamentos de multas mediante ao não cumprimentos de regras estabelecidas. O valor atual destas multas é de 2.500,00.

A meta é eliminar inspeção de peças recebidas na fábrica.

\subsection{Fornecedores}

Enquanto o Fornecedor 1 apresenta 40 pessoas voltadas às atividades tecnológicas e o Fornecedor 2 apresenta cerca de 15 (sendo que em ambos o número de pessoas integrantes é crescente), a empresa nacional não possui um setor com esta finalidade. No caso do Fornecedor 3, há um dos proprietários (engenheiro civil com pós-graduação em engenharia de materiais) pesquisando novos materiais a serem aplicados nos produtos.

\subsubsection{Fornecedor 1}

Empresa multinacional pertencente predominantemente ao segmento dos componentes metálicos, o Fornecedor 1 desenvolve e produz compressores, componentes importantes para os produtos da linha branca, que as montadoras projetavam e produziam internamente. Desse modo, pode-se dizer que as montadoras apresentam certo know-how sobre o conteúdo tecnológico desses componentes.

Os produtos do Fornecedor 1 são padronizados, pois são exportados para diversos países. Cabe mencionar que, do total do volume produzido pela empresa, aproximadamente $70 \%$ é exportado.

Para manter-se competitiva, a empresa tem buscado diversificar seus modelos de produtos. Além da flexibilidade de produtos, redução de custos é outra prioridade competitiva deste fornecedor.

Neste contexto, a empresa prioriza as capacidades de Inovação, Investimento (Aquisição),

\section{de Produção e Adaptação e de Proteção.}

Considerando inicialmente a Capacidade de Inovação, ressalta-se a transferência do centro de P\&D da matriz estrangeira para a subsidiária (Fornecedor 1).

Com isso, houve um acréscimo do número de pessoas envolvidas em atividades tecnológicas na subsidiária, assim como o aumento das atividades realizadas. Ao mesmo tempo, encerraram-se as atividades anteriormente realizadas na matriz.

Após tais mudanças, a diversidade de modelos de produtos cresceu consideravelmente, disse o Administrador Chefe de P\&D. 
Devido ao fato das montadoras apresentarem know-how relativo ao funcionamento de compressores, elas acabam indicando para o Fornecedor 1 algumas tendências para novos modelos de produtos, muitas vezes trazendo informações da concorrência. Assim, clientes são fontes importantes de conhecimentos tecnológicos para a empresa.

No que se refere à Capacidade de Aquisição, tem-se que, além dos clientes, a empresa busca conhecimentos junto à matriz estrangeira, universidades e seus fornecedores, especialmente aqueles que dominam a tecnologia das peças que lhe entregam.

Merece destaque, no caso do Fornecedor 1, a Capacidade de Produção e Adaptação. A empresa criou um setor robusto, denominado Engenharia Industrial Avançada, responsável pela implementação dos novos produtos na fábrica e pela melhoria dos processos existentes. Suas atividades, em geral, integram os assuntos da Engenharia ao da Produção, na medida em que seus membros participam das atividades de ambos os setores mencionados.

Quanto à Capacidade de Exploração, a empresa não tem demonstrado esforços no sentido de ampliá-la.

Por outro lado, proteger conhecimentos adquiridos (Capacidade de Proteção) é uma preocupação para o fornecedor. Além do sigilo de informações imposto aos funcionários, a empresa busca patentear produtos por ela desenvolvidos.

As mudanças técnicas em produtos consistem em melhorias incrementais realizadas nos modelos já existentes (outrora desenvolvidos na matriz).

As mudanças técnicas realizadas nos processos de produção são, em sua maioria, melhorias incrementais que podem (ou não) estar relacionadas à introdução de um novo modelo de produto (desenvolvido localmente com o aval da matriz estrangeira).

\subsubsection{Fornecedor 2}

O Fornecedor 2 pertence ao segmento dos componentes eletrônicos e fornece peças para montadoras automobilísticas e de linha branca instaladas no Brasil.

A prioridade competitiva da empresa é a flexibilidade, tanto de volume de produção, quanto a de mix de produtos.

Para isso, o Fornecedor 2 vem direcionando esforços no sentido de ampliar suas capacidades

\section{de Inovação e de Investimento (ou de Aquisição de tecnologias).}

Em sua planta há um setor de Engenharia, que desenvolve localmente (sem conhecimentos tecnológicos vindos da matriz estrangeira) produtos e processos de produção.

Neste sentido, a empresa ampliou o número de pessoas envolvidas em atividades de DP, assim como o número de projetos em andamento (Capacidade de Inovação). 
Considerando a amostra de empresas aqui estudada, o Fornecedor 2 se relaciona com a Montadora A, que lhe cede os projetos dos produtos. No entanto, seu principal cliente é outra montadora, não estudada neste trabalho, para a qual a empresa desenvolve os projetos de produtos.

A busca por novos conhecimentos tecnológicos ocorre junto à universidades, centros de pesquisas e os próprios fornecedores (Capacidade de Investimento/Aquisição).

Quanto às demais capacidades (Capacidade de Produção e Adaptação e Capacidades de Exploração e Proteção), a empresa não tem demonstrado esforços no sentido de ampliá-las.

As mudanças técnicas em produtos consistem em melhorias incrementais realizadas nos modelos de produtos já existentes.

As mudanças técnicas realizadas nos processos de produção são, em sua maioria, melhorias incrementais que podem (ou não) estar relacionadas à introdução de um novo modelo de produto (desenvolvido localmente).

\subsubsection{Fornecedor 3}

O Fornecedor 3 é uma empresa nacional de pequeno porte que, no setor de linha branca, atende exclusivamente a Montadora A.

As máquinas e equipamentos pertencem à montadora e a empresa opera com margens de lucro que os proprietários consideram muito baixas. Cabe lembrar que a empresa fornece peças também ao setor de Construção Civil, no qual opera com margens de lucro bem maiores, segundo um dos proprietários.

Neste contexto, a empresa precisa adequar-se às exigências da Montadora A, que lhe cobra por reduções de custos e flexibilidade de volume de produção.

Para isso, a empresa enfatiza as Capacidades de Inovação e de Investimento (Aquisição).

O Fornecedor 3 é administrado pelos três irmãos - proprietários - que são os responsáveis por todos os assuntos que dizem respeito à empresa (pesquisa de novos materiais, volumes produzidos, finanças, suprimentos, etc).

A empresa recebe o projeto dos produtos da montadora e se responsabiliza pelos processos de produção, assim como medidas para reduzir custos (ex.: aplicação de novos materiais, reciclagem de materiais, etc).

Neste contexto, um dos administradores realiza pesquisas para aplicações de novos materiais, (Capacidade de Inovação) e conta com o apoio (informal) da universidade onde recebeu o título de Mestre (Capacidade de Investimento/Aquisição).

Quanto às demais capacidades (Capacidade de Produção e Adaptação e Capacidades de Exploração e Proteção), a empresa tem a necessidade de ampliá-las.

As mudanças técnicas em produtos são feitas pelo cliente, que é responsável pelos projetos. 
As mudanças técnicas realizadas nos processos de produção são, em sua maioria, melhorias incrementais que podem (ou não) estar relacionadas à introdução de um novo modelo de produto (desenvolvido pela montadora).

\section{Análise dos casos}

A amostra de empresas estudadas envolve três fornecedores pertencentes ao primeiro nível de suprimentos de montadoras da linha branca.

Dentre eles, dois são empresas subsidiárias de multinacionais e um é empresa de capital 100\% nacional. Este último apresenta menor porte e atende (quase) exclusivamente à uma única montadora:

- Fonecedor 1: clientes indicam tendências sobre os novos modelos dos produtos; a empresa desenvolve projetos de produtos em parceria com universidades e centros de pesquisa; recebe consultorias de universidades para realização de testes; fornecedores de componentes importantes são fontes de conhecimento, especialmente aqueles que dominam a tecnologia dos produtos que lhe entregam.

- Fornecedor 2: idem Fornecedor 1 (seu principal cliente é outra montadora, não estudada neste trabalho, para a qual a empresa desenvolve os projetos de produtos).

- Fornecedor 3: o cliente (Montadora A) desenvolve os projetos de seus produtos e lhe passa o know-how envolvido nos processos; há relação com universidade, que embora informal, é constante e vem gerando inovações nos materiais utilizados.

$\mathrm{Na}$ amostra estudada, apenas o Fornecedor 1 realiza mudanças técnicas em produtos, ficando nos demais casos por conta das montadoras-clientes. Nenhum dos fornecedores explora tecnologias desenvolvidas por outras empresas.

Foi possível observar também que a montadora procurou manter relações de longo prazo com fornecedores criteriosamente selecionados e avaliados, na maioria dos casos, comuns à diversas montadoras.

A Montadora A: a) possui apenas um fornecedor por item adquirido externamente, b) cedelhes (em parte dos casos) as máquinas e equipamentos necessários, c) adquire produtos de maior valor agregado (módulos) e pretende expandir tal estratégia para mais componentes, d) possui fornecedores exclusivos e d) possui em sua cadeia um número considerável de empresas pequenas. Assim, pode-se inferir que ela adota um relacionamento bastante estreito com boa parte de seus fornecedores, relações estas em que as trocas de conhecimentos são mais intensas - Montadora A deve passar conhecimentos tecnológicos para sua cadeia de fornecedores.

A montadora apresenta um conjunto de médias e pequenas empresas localizadas próximas à sua planta, algumas delas fornecendo-lhe peças exclusivamente (ou quase exclusivamente). A 
montadora ainda incentiva o intercâmbio de peças entre estes fornecedores, para que elas cheguem até suas linhas de produção com maior valor agregado (módulos).

Para facilitar essas relações da montadora com os fornecedores próximos, foi criado na empresa um cargo para a área de Compras, já que este setor é situado em outra planta do grupo no Brasil, onde essa função é centralizada. Vale ressaltar que parte dos fornecedores estão localizados próximos desta outra planta e atendem a ambas.

Em geral, as montadoras apresentam fornecedores comuns e que, no que se refere aos componentes de maior conteúdo tecnológico, são produzidos (e em alguns casos desenvolvidos) por fornecedores de maior porte.

Por outro lado, sendo os fornecedores pequenos mais dependentes da montadora que lhe presta auxílio, devem responder mais prontamente às exigências de sua cliente, o que pode ajudar a montadora em termos de flexibilidade de volume e mesmo de mix de produtos (quando novos produtos requerem novos componentes que são terceirizados). A montadora pode ainda aprender com as interações entre fornecedores.

Assim, fornecedores podem também gerar conhecimentos, de modo que o auxílio prestado pela montadora pode ser também entendido como esforços no sentido de ampliar a capacidade de Investimento (Aquisição). Para ilustrar esse fato, recorremos ao Fornecedor 3. Esta empresa recebe da Montadora A as máquinas, equipamentos, projetos dos produtos/processos e visitas de engenheiros que acompanham toda a produção dos componentes. Em contrapartida, um dos engenheiros do Fornecedor 3 pesquisa junto à universidade a utilização de novos materiais a serem aplicados nos produtos, o que tem gerado melhorias e reduções de custos.

\section{Considerações Finais}

Optamos em apresentar as conclusões em diferentes planos (ou níveis de abrangência) de resultados.

Em um primeiro plano estão as principais tendências que o setor de linha branca vem apresentando.

A indústria de linha branca chegou ao Brasil no final dos anos 40 e o setor ficou caracterizado por a) um número reduzido de grandes empresas familiares de capital nacional; e b) dois grandes grupos transnacionais, que dominavam, direta ou indiretamente, as demais companhias, formando um oligopólio.

A partir da década de 90, grandes grupos internacionais voltaram-se aos mercados emergentes como a América Latina, o Leste Europeu e o Sudeste Asiático. As empresas brasileiras foram gradualmente sendo incorporadas por poucos e grandes grupos estrangeiros. Uma das 
principais conseqüências foi a desnacionalização do capital produtivo que, até então, tinha forte participação de empresas familiares nacionais.

As empresas foram então sendo adquiridas pelos grandes grupos e os conhecimentos tecnológicos locais acumulados (assim como as instalações) foram de certa forma aproveitados, ao mesmo tempo em que as empresas foram se modernizando e tendo acesso a inovações. Vale ressaltar, no entanto, que as matrizes estrangeiras adotaram diferentes estratégias de divisão de atividades de $\mathrm{P} \& \mathrm{D}$, sendo em alguns casos mais descentralizadas que em outros.

Considerando que algumas empresas sejam mais descentralizadas que outras e que, portanto, algumas realizem localmente mais atividades de $\mathrm{P} \& \mathrm{D}$, pode-se dizer que algumas montadoras tendem a contribuir mais do que outras para o desenvolvimento tecnológico brasileiro.

Foram realizados estudos de caso em duas montadoras do setor de linha branca. Além dessas empresas, foram estudados três fornecedores diretos (de primeiro nível). Dois dos fornecedores são empresas subsidiárias de multinacionais, e um de capital de origem nacional.

Dentre os fornecedores estudados, apenas os multinacionais apresentaram capacidade para desenvolver projetos de produtos e de processos.

Em um segundo plano estão os resultados da pesquisa relacionados às Estratégias Tecnológicas das empresas estudadas.

As atividades tecnológicas dos fornecedores são, em grande medida, orientadas pelas atividades de DP das montadoras, já que estas, quando vão lançar um novo modelo de produto, passam a alguns fornecedores as especificações (ou projetos) para que estes também inovem seus componentes.

Verificou-se que apenas os fornecedores multinacionais da amostra apresentam capacidade tecnológica para desenvolver projetos de produtos/ processos.

No terceiro plano de resultados tem-se a ET no contexto da cadeia de suprimentos.

A Montadora A tende a contribuir para o desenvolvimento tecnológico brasileiro, na medida em que realiza atividades locais de P\&D, e ainda, o faz em conjunto com fornecedores (sendo a maior parte deles comuns às diversas montadoras). Dentre esses fornecedores, tem-se um conjunto de empresas nacionais de pequeno porte, as chamadas empresas familiares.

A Montadora A deve despender esforço para desenvolver fornecedores menos capacitados (passando-lhes conhecimentos) e garantir um desempenho adequado dos mesmos. Assim, pode-se dizer que a cadeia de suprimentos influencia sua ET.

Outras montadoras precisariam ser estudadas para avaliar os impactos de suas cadeias de suprimentos nas ETs. As montadoras que possuírem uma proporção maior de fornecedores de 
grande porte e mais capacitados tecnologicamente, por sua vez, devem despender esforços relativamente maiores nas negociações (das transações) com fornecedores, mas seu esforço para desenvolvê-los seria muito menor.

\begin{abstract}
The literature on Technology Strategy (TS) is still incipient, with major gaps when dealing with the relationships between clients' and suppliers' TS. In such context, the aim of this paper is to identify and analyze the TS undertaken by a domestic appliance assembler, in the context of its supply chain. The main findings indicate that the assembler tends to contribute to local technological development, once that it accomplished local $R \& D$, together with its main suppliers. Among these suppliers, we could find companies that own the technological contents of important parts, as well as a set of small-sized Brazilian companies (family businesses). The assembler must make efforts to develop less capable suppliers (transferring knowledge) and assuring their suitable performance. Thus, it can be said that the supply chain (composed of a heterogeneous set of companies) exerts influence on its TS.
\end{abstract}

Key-words: Technology Strategy, Product Development, Strategy, Domestic Appliance Industry.

\title{
Referências Bibliográficas
}

ALVES FILHO, A.G.; CERRA, A. L.; MAIA, J. L.; SACOMANO NETO, M.; BONADIO, P.V.G. . Pressupostos do Gerenciamento da Cadeia de Suprimentos: evidências de estudos sobre a indústria automobilística. Gestão \& Produção, v.11, n.3, p.275-288, set-dez, 2004.

AlVES FILHO, A.G.; RACHID, A.; DONADONE, J. C.; MARTINS, M. F.; TRUZZI, O. M. S.; BENTO, P. E. G.; VANALLE, R. M... O consórcio modular e seus impactos na cadeia de suprimentos da fábrica de motores VW-São Carlos. Relatório Final, Projeto Temático, Processo FAPESP 97/13071-9, 2001.

ALVES FILHO, A.G. Estratégia tecnológica, desempenho e mudança: estudo de caso em empresas da indústria de calçados. 1991. Tese (Doutorado em Engenharia de Produção) - Escola Politécnica, Universidade de São Paulo. São Paulo.

ASSUMPÇÃO, M. R. P. Reflexão para Gestão Tecnológica em Cadeias de Suprimentos. Gestão \& Produção. v.10, n.3, p.345-362, dez 2003.

BELL, R. M.; PAVITT, K. Technological accumulation and industrial growth: contrasts between developed and developing countries. Industrial and Corporate Change, p.157 - 210, 1993.

BOEHE, D.M. Desenvolvimento de Produtos em subsidiárias de empresas multinacionais no Brasil. Revista de Administração de Empresas - RAE. Jan./mar. 2007. p.33-45.

CERRA, A.l. Estratégias Tecnológicas em cadeias de suprimentos dos setores automobilístico e de linha branca. Relatório FAPESP (Processo 05/59798-5), 2008.

CHOPRA, S.; MEINDL, P. Gerenciamento da Cadeia de Suprimentos - Estratégia, Planejamento e Operação. São Paulo: Prentice Hall, 2003.

CHRISTOPHER, M. Logistics and supply chain management. London: Pitman Publishing, 1992.

COHEN, W.M.; LEVINTHAL, D.A. Absorptive capacity: a new perspective on learning and innovation. Administrative Science Quarterly. Special Issue - Technology, Organizations and Innovation. v.35, n.1, p.128-152, March 1990.

DAHLMAN, C.J.; ROSS-LARSON,B.; WESTPHAL, L.E. Managing technological development: lessons from the newly industrializing countries. World Development, v.15, n.6, 1987. p.759-775.

cross ${ }^{\text {ref }}$ 
DAVENPORT, S.; CAMPBELL-HUNT, C.; SOLOMON, J. The dynamics of Technology Strategy: an exploratory study. R\&D Management, V.33, n.5, 2003.

cross ${ }^{\text {ref }}$

FERNANDES, J.M. et al. Cross-functional teams and concurrent engineering: contributions to the development of product design through multidisciplinary integration using CAD systems. Product: Management \& Development. Vol.3, n.1, p. 5- 9, august 2005.

FORD, D. Develop your strategy. Engineering Management Review, New York, vol. 17, No. 3, p. 16-26, September 1989.

FORD, D.; THOMAS, R. Technology strategy in networks. International Journal Technology Management, vol.14, nos 6/7/8, 1997. p. 596-612.

GIBBONS, P.T.; O’CONNOR, T. Strategic posture, technological strategy and performance. Journal of Enterprising Culture. V.11, n.2, june 2003. p.131-146.

cross ${ }^{\text {ref }}$

HAGEDOORN, J.; NARULA, R. Choosing organizational modes of strategic technology partnering: international and sectoral differences. Journal of International Business Studies. p. 265-283, Second Quarter, 1996.

HANDFIELD, R. B. et al. Avoid the pitfalls in supplier development. Sloan management Review. v.41, n.2, p.37-49, Winter, 2000.

HARO-DOMÍNGUEZ, M.del C.; ARIAS-ARANDA, D.; LLORÉNS-MONTES, F.J. MORENO, A.R. The impacto f absorptive capacity on technological acqisitions engineering consulting companies. Technovation 27 (2007) 417-425.

cross ${ }^{\text {ref }}$

IGLECIAS, L. Um modelo para formulação de Estratégia Tecnológica: o caso de uma montadora na indústria automobilística. 2001. Dissertação (Mestrado em Engenharia de Produção) - Universidade Federal de São Carlos.

LAMMING, R. Beyond partnership - strategies for innovation and lean supply. 294 p. The Manufacturing Practioner Series, 1993.

LAMBERT, D.M.; EMMELHAINZ, M.A.; GARDNER, J.T. Developing and implementing Supply Chain Partnerships. The International Journal of Logistics Management. V.9, n.2, p. 1-17, 1996.

cross ${ }^{\text {ref }}$

LORENZONI, G.; LIPPARINI, A. The leveraging of interfirm relationships as a distinctive organizational capability: a longitudinal study. Strategic Management_Journal, 20. p.317-338, 1999.

cross ${ }^{\text {ref }}$

MARTINEZ, M. A construção da qualificação: um estudo de caso na linha branca. Dissertação (Mestrado em Engenharia de Produção). Departamento de Engenharia de Produção. Universidade Federal de São Carlos. São Carlos, 2004. $87 \mathrm{p}$.

MARTINS, M.F. Análise da função suprimentos nas empresas de manufatura. O caso das empresas da indústria de linha branca. 1999. Tese (Doutorado em Engenharia Mecânica). Escola de Engenharia de São Carlos- EESC-USP. São Carlos-SP. 1999. 196p.

MIRANDA, J.L. Procedimento para análise da viabilidade da utilização de operadores logísticos na cadeia de suprimentos. Tese de Doutorado. EESC- USP, 2002.

PORTER, M.E. Competitive advantage. New York: Macmillam, 1985.

RIEG, D. L. Estratégia Tecnológica, Empresa de Base Tecnológica e Desempenho Inovador: o caso das empresas do setor médico-hospitalar de São Carlos e Ribeirão Preto. 2004. Tese (Doutorado wm Engenharia de Produção). 162p.UFSCar. São Carlos-SP .

ROTTA, I.S. Mini-fábrica: uma nova proposta de arranjo produtivo e organizacional híbrido em uma empresa do setor eletroeletrônico. Tese (Doutorado em Engenharia de Produção). Departamento de Engenharia de Produção. Universidade Federal de São Carlos. São Carlos, 2004. 268p. 
SANTOS, A.C.; FORCELLINI, F.A. Avaliação do envolvimento dos fornecedores no processo de desenvolvimento de produtos (PDP) - a partir d um modelo de referencia para a indústria de alimentos.In: Congresso Brasileiro de Gestão de Desenvolvimento de Produtos. Anais do V CBGDP. Curitiba, PR, agosto de 2005.

TAN, K.C. Supply Chain Management: Practices, concerns, and performance issues. The Journal of Supply Chain Management - A Global Review of Purchasing and Supply. p.42-53, Winter, 2002.

TRATT, S.R.B.; MORAES, M.C.B.; ALPERSTEDT, G.D. A terceirização de atividades-fim em uma siderúrgica: ameaça ou oportunidade? Anais do XI SIMPOI / FGV-EAESP. São Paulo, 2006.

ZAHRA, S. A; NIELSEN, A. P.; Sources of capabilities, integration and technology commercialization. Strategic Management Journal, 23. p.377-398, 2002.

cross ${ }^{\text {ref }}$

ROTTA, I.S. Mini-fábrica: uma nova proposta de arranjo produtivo e organizacional híbrido em uma empresa do setor eletroeletrônico. Tese (Doutorado em Engenharia de Produção). Departamento de Engenharia de Produção. Universidade Federal de São Carlos. São Carlos, 2004. 268p.

WESTPHAL, L.E.; KIM, L. e DAHLMAN, C.J. Reflections on the Republic of Korea's acquisition of technological capability, In: ROSENBERG, N.; FRISCHTAK, C. International technology transfer: concepts, measures, and comparisons. New York: Praeger, 1985.

Nome completo: Aline Lamon Cerra

Filiação institucional: Universidade Federal de São Carlos

Departamento: Engenharia de Produção

Função ou cargo ocupado: Estudante de Pós-Doutoramento

Endereço completo para correspondência: Rod. Washington Luis KM, 235, CEP - 13560-000 - São

Carlos - SP

Telefones para contato: (16) 3351-8239

e-mail: alinelc@terra.com.br

Nome completo: Jonas Lucio Maia

Filiação institucional: Universidade Federal de São Carlos

Departamento: Engenharia de Produção

Função ou cargo ocupado: Estudante de Doutorado

Endereço completo para correspondência: Rod. Washington Luis KM, 235, CEP - 13560-000 - São

Carlos - SP

Telefones para contato: (16) 3351-8239

e-mail: jonasmaia@dep.ufscar.br

Nome completo: Alceu Gomes Alves Filho

Filiação institucional: Universidade Federal de São Carlos

Departamento: Engenharia de Produção

Função ou cargo ocupado: Professor Titular 
Endereço completo para correspondência: Rod. Washington Luis KM, 235, CEP - 13560-000 - São Carlos - SP

Telefones para contato: (16) 3351-8239

e-mail: alceu@power.ufscar.br 